\title{
SPHERICAL TRIGONOMETRY IN THE ASTRONOMY OF THE MEDIEVAL KE- RALA SCHOOL
}

\author{
KIM PLOFKER \\ Brown University
}

Although the methods of plane trigonometry became the cornerstone of classical Indian mathematical astronomy, the corresponding techniques for exact solution of triangles on the sphere's surface seem never to have been independently developed within this tradition. Numerous rules nevertheless appear in Sanskrit texts for finding the great-circle arcs representing various astronomical quantities; these were presumably derived not by spherics per se but from plane triangles inside the sphere or from analemmatic projections, and were supplemented by approximate formulas assuming small spherical triangles to be plane.

The activity of the school of Mādhava (originating in the late fourteenth century in Kerala in South India) in devising, elaborating, and arranging such rules, as well as in refining formulas or interpretations of them that depend upon approximations, has received a good deal of notice. (See, e.g., R.C. Gupta, "Solution of the Astronomical Triangle as Found in the Tantra-Samgraha (A.D. 1500)", Indian Journal of History of Science, vol.9,no.1,1974, 86-99; "Mādhava's Rule for Finding Angle between the Ecliptic and the Horizon and Äryabhața's Knowledge of It." in History of Oriental Astronomy, G.Swarup et al., eds., Cambridge: Cambridge University Press, 1985, pp. 197-202.) This paper presents another such rule from the Tantrasangraha (TS; ed. K.V.Sarma, Hoshiarpur: VVBIS\&IS, 1977) of Mādhava's student's son's student, Nīlkaṇtha's Somayājin, and examines it in comparison with a similar rule from Islamic spherical astronomy.

Nilkantha's rule is given in the sixth chapter of the $T S$, a section devoted to the calculation of the patas, ominous astrological events determined by the relation of the longitudes and declinations of the Sun and the Moon. Generally, for this purpose the lunar declination is considered to be its ecliptic declination $\delta_{1}$ (see Fig.1) rather than its "true" declination $\delta=\beta_{*} \pm \delta_{1}\left(\lambda_{*}\right)$; but even when the true declination is explicitly required, the distinction between ecliptic and polar coordinates is usually not made, so the quantity is given by the approximation $\delta \approx \beta \pm \delta_{1}(\lambda)$. Nìlkanțha is, as far as I know, the first Indian astronomer to substitute for both these expedients a more complicated rule, as follows (TS 6, 4-6):

When one has multiplied the Sine of the [lunar] latitude by the Cosine of the maximum declination $\left[\epsilon\right.$, the obliquity of the ecliptic] and the given declination $\left[\delta_{1}\right]$ by the Cosine of that [latitude], both [products] are divided by the Radius. They are to be added or subtracted.

[Their] sum (when in the same direction) or difference (when in different directions) is [the Sine of] the true declination $[\delta]$. The Cosine of the true declination may be considered as the "day-sine" $[r$, radius of a small cirlce $]$ in the latitude circle.

It should be taken for the true declination by those most knowledgeable in the calculation of the sphere.

In other words,

$$
\frac{\operatorname{Sin} \beta \cdot \operatorname{Cos} \epsilon}{R} \pm \frac{[\operatorname{Sin}] \delta_{1}(\lambda) \cdot \operatorname{Cos} \beta}{R}=[\operatorname{Sin}] \delta
$$


Due to the brevity of the verses and their commentary and the lack of a worked example or proof, it is not entirely certain which of the omitted quantities (supplied here in square brackets) the author expected the reader to supply, and the manner in which Nilkantha derived the rule is not clear at all. (He may, of course, owe it to one of his predecessors or colleagues among those "most knowledgeable in the calculations of the sphere", or "golavittama"; this may in fact be a reference to Mādhava himself, who is sometimes styled "the Golavid" by later members of his school.) In this context, it is interesting to note that a strinkingly similar formula for $\delta$ is given in Ibn Yunis' Häkimi Zinj of 1003 (cf. David A. King, The Astronomical Works of Ibn Yunus, Ph.D. dissertation, Yale University, 1972, pp. 290-293).

Ibn Yunis' rule may be expressed as follows:

$$
S_{1}=\frac{\operatorname{Sin} \delta_{1}(\lambda) \cdot \operatorname{Cos} \beta}{R}, \quad S_{2}=\frac{\operatorname{Sin} \beta \cdot \operatorname{Cos} \epsilon}{R}, \quad \operatorname{Sin} \delta=S_{1} \pm S_{2}
$$

There is no doubt that the Hakimi Zinj and the Tantrasangraha are here prescribing essentially the same procedure for finding the declination. Unfortunately, this tells us little about the probability of the method's direct transmission from the Islamic to the Keralese tradition, as the independent rederivation of a fairly complicated spherics formula using only the techniques of plane trigonometry is by no means a surprising feat for a mathematician of Nīlkantha's caliber (elusive though it may prove for lesser intellects, including, so far, that of the present author). But in light of existing evidence for the awareness of some elements of Islamic astronomy among the members of Mādhava's school, the possibility of an ultimate Arabic or Persian source for the rule in the $T S$ cannot be entirely discounted.

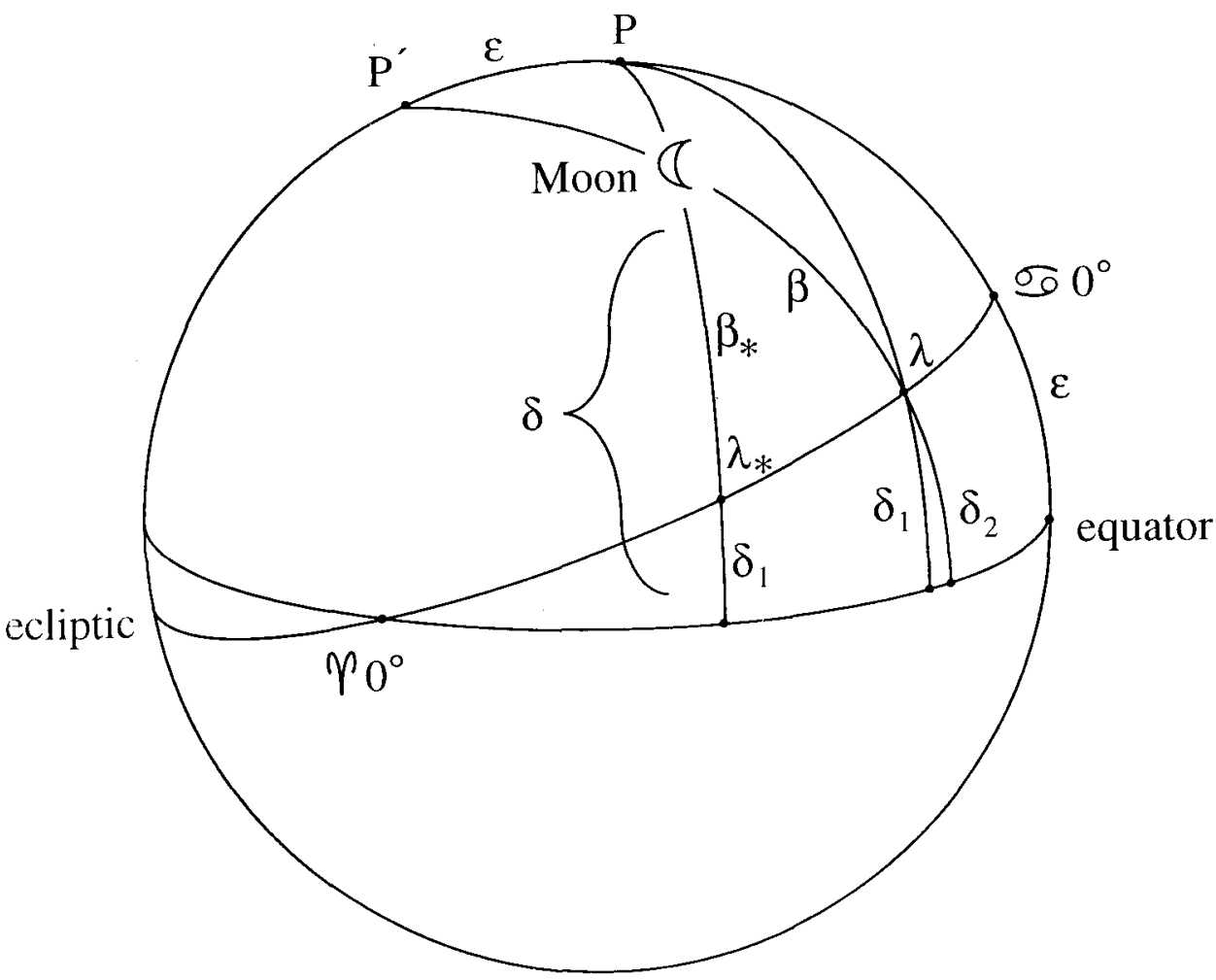

Fig. 1 